\title{
Acustical studies of interactions in the binary mixtures of ethylmethyl ketone (EMK) and N,N- dimethylformamide (DMF) through ultrasonic measurements at different temperatures
}

\author{
Baljeet Singh Patial ${ }^{*}$ \\ Department of Chemistry, BTC DAV College, Banikhet (Dalhousie), Distt. Chamba, H.P.(India) \\ *E-mail address: dr.baljeetsinghpatial@yahoo.in
}

\begin{abstract}
Ultrasonic velocities $(u)$, densities $(\rho)$ and viscosities $(\eta)$ are measured in respect of ethylmethylketone (EMK) and N,N-dimethylformamide (DMF) over the entire composition at 298, 308and $318 \mathrm{~K}$. Attempt have been made to extract the information with respect to various kind of intermolecular interactions, such as H-bonding, dipole-dipole, solute -solvent, dispersion type interactions existing between these two components from the following acoustical parameter when examined as a function of solvent composition at different temperatures: adiabatic compressibility $(\beta)$, specific acoustic impedance $(Z)$, intermolecular free length $\left(L_{f}\right)$, molar sound velocity $\left(R_{m}\right)$, wada's constant $(\mathrm{W})$, viscous relaxation time $(\tau)$, free volume and internal pressure $\left(\pi_{\mathrm{i}}\right)$.
\end{abstract}

Keywords: ultrasonic velocities; densities; viscosities; ethylmethylketone (EMK); N,Ndimethylformamide (DMF); different temperatures

\section{INTRODUCTION}

Ultrasonic methods find extensive applications for characterizing aspects of physicochemical behavior such as nature of molecular interaction in pure liquid as well As liquid mixtures and find application in several industrial and technological processes ${ }^{1-2}$. The study of thermodynamic properties of binary liquid mixtures has proved to be a useful tool in elucidating structural interactions of components ${ }^{3-4}$. Derived parameters such as internal pressure and free volume studies will be useful to know the molecular interactions of the systems. Ultrasonic velocity measurements have been successfully employed to detect and assess weak and strong molecular interactions in binary liquid mixtures ${ }^{5-6}$. In this paper an attempt is made to investigate the ultrasonic studies of binary mixture systems of ethylmethylketone (EMK) and N, N-dimethylformamide (DMF) at 298, 308and 318. K. Both EMK and DMF belong to similar class of dipolar solvents. In pure state both have no tendencies to associate through dipole-dipole interactions which have been observed in dimethyl sulphoxide (DMSO) ${ }^{7,8}$.

In order to understand the molecular interactions between the participating of components of these mixtures ultrasonic velocities, densities and viscosities are measured over the entire composition range at 298, 308and $318 \mathrm{~K}$. using the experimental data, various 
acoustical parameters like adiabatic compressibility $(\beta)$, specific acoustic impedance $(Z)$, intermolecular free length $\left(\mathrm{L}_{\mathrm{f}}\right)$, molar sound velocity $\left(\mathrm{R}_{\mathrm{m}}\right)$, wada's constant $(\mathrm{W})$, viscous relaxation time $(\tau)$, free volume and internal pressure $\left(\pi_{\mathrm{i}}\right)$ are estimated. These parameters are used to interpret the intermolecular interactions such as H-bonding, dipole-dipole, solute solvent, dispersion type interactions existing between these two components of binary mixtures.

\section{EXPERIMENTAL}

Water required for the calibration of the viscometer, pycnometer and ultrasonic velocity liquid cell was twice distilled over acidified $\mathrm{KMnO}_{4}$ through a $750 \mathrm{~mm}$ long vertical fractionating column. Middle fraction of about 800-1000 $\mathrm{ml}$ was collected and stored in coloured bottle for use. The conductivity of distilled water was found to be $1-2 \times 10^{-6} \mathrm{~s}$. The value of ultrasonic velocity for the conductivity water was found to be $1490 \mathrm{~m} / \mathrm{s}$ at $298.15 \mathrm{~K}$ at $1 \mathrm{MHz}$, which is agreed well with literature value ${ }^{9}$.

Ultrasonic velocity were measured using interferometer (Model-81, supplied by Mittal Enterprises, New-Delhi) operating at a frequency of $1 \mathrm{MHz}$, which is a direct and simple device for measuring ultrasonic velocity in liquids.

Density measurement were carried out within a precision of $\pm 0.01 \%$ using sealable pycnometer of capacity $20 \mathrm{~cm}^{3}$, of pure solvents as well as solvent mixtures in a water thermostant, whose temperature was kept constant within the range of $\pm 0.5 \%$.

Viscosity measurement were carried out with a precision of $\pm 0.2 \%$ by using an calibrated Ubbelehode bulb level viscometer, whose flow time for doubly distilled water was found to be $584.2 \pm 0.1 \mathrm{~s}$ at $298.15 \mathrm{~K}$. No kinetic energy correction was applied as the flow time was greater than $400 \mathrm{~s}$. The values of viscosity and density of pure EMK and DMF were found to be in good agreement as reported in literature ${ }^{10}$.

Dimethylformamide (DMF) and ethylmethylketone (EMK) (both from Research Laboratories Pvt Ltd Bombay) have been purified by the methods reported earlier ${ }^{11}$.

Different acoustical parameters such as adiabatic compressibility $(\beta)$, specific acoustic impedance $(Z)$, intermolecular free length $\left(L_{f}\right)$, molar sound velocity $(R m)$, wada's constant $(\mathrm{W})$, viscous relaxation time $(\tau)$, free volume $\left(\mathrm{V}_{\mathrm{f}}\right)$ and internal pressure $\left(\pi_{\mathrm{i}}\right)$ have been calculated at different temperatures, with the help of ultrasonic velocity $(u)$, density $(\rho)$ and $\operatorname{viscosity}(\eta)$ values using the following relations ${ }^{12,14}$ :

\section{Adiabatic compressibility ( $\beta$ )}

The adiabatic compressibility values for various compositions of the binary solvent mixtures have been calculated from the measured ultrasonic velocities $(u)$ and densities $(\rho)$

$$
\beta=\frac{1}{u^{2} \rho}
$$

Free length $\left(\mathbf{L}_{\mathbf{f}}\right)$

The free length in a solvent mixture is related to ultrasonic velocity and density as:

$$
L_{f}=K_{T} \sqrt{\beta}
$$


Where $K_{T}$ is time dependent constant whose value is $199.53 \times 10^{-8}$ in MKS system.

\section{Acoustic Impedance (Z)} relation:

The specific acoustic impedance is related to density and ultrasonic velocity by the

$$
Z=u \rho
$$

\section{Relaxation Time $(\tau)$}

Relaxation can be calculated from viscosity coefficient $(\eta)$, density and ultrasonic velocity of binary mixtures and given by

$$
\tau=\frac{4 \eta}{3 \rho u^{2}}
$$

\section{Free Volume $\left(\mathbf{v}_{\mathrm{f}}\right)$}

The free volume of binary mixture is given by

$$
V_{f}=\left[\frac{M_{e f f} u}{K \eta}\right]^{3 / 2}
$$

Where $\mathrm{K}$ is time independent constant whose value is $4.28 \times 10^{9}$ in MKS system and $\mathrm{M}_{\mathrm{eff}}$ effective molecular weight of the liquid is given by

$$
M_{\text {eff }}=X_{1} M_{1}+X_{2} M_{2}
$$

Where $X_{1} \& X_{2}$ are the mole fraction of first and second components and $M_{1} \& M_{2}$ are the molecular weights of first and second components respectively.

Wada's Constant (W)

Wada's constant can be calculated as

$$
W=\frac{M_{e f f} \beta^{-\frac{1}{7}}}{\rho}
$$

Molar Sound velocity $\left(\mathbf{R}_{\mathrm{m}}\right)$

Malar sound velocity of the mixture is given by

$$
R_{m}=\left[\frac{M_{e f f}}{\rho}\right] u^{\frac{1}{s}}
$$

Internal Pressure $\left(\boldsymbol{\pi}_{\mathbf{i}}\right)$

Internal pressure is given by 


$$
\pi_{i}=\frac{b R T[K \eta]}{M_{\text {eff }}^{\frac{7}{6}}} \rho^{\frac{2}{3}}
$$

Where, $\mathrm{b}$ is the cubic packing factor which is assumed to be 2 in liquid systems.

$\mathrm{K}=4.28 \times 10^{9}$ and is independent to the nature of liquid.

$\mathrm{R}$ is gas constant.

\section{RESULTS AND DISCUSSION}

The ultrasonic velocity, density and viscosity were measured for DAMF, EMK and $\mathrm{EMK}+\mathrm{DMF}$ mixtures containing $0,10,20,30,40,50,60,70,80,90,100$ mole $\%$ by volume of EMK at $1 \mathrm{MHz}$ frequency and at 298, 308 and $318 \mathrm{~K}$.

The density, viscosity and ultrasonic velocity were found to vary linearly with solvent composition. Their values are, however, maximum in pure DMF and decrease with increase of EMK content. This trend suggests that the dipole -dipole interactions are more at higher concentration of DMF in the binary mixture. With the increase in temperature, decrease in velocity, density and viscosity observed. This trend reveals that at higher temperature the molecular interactions between the components are low.

\section{Acoustical Parameters}

The experimentally determined values of ultrasonic velocity $(u)$, density $(\rho)$ and viscosity $(\eta)$ along with calculated values of different acoustical parameters such as adiabatic compressibility $(\beta)$, specific acoustic impedance $(Z)$, intermolecular free length $\left(L_{f}\right)$, molar sound velocity $(\mathrm{Rm})$, wada's constant $(\mathrm{W})$, viscous relaxation time $(\tau)$, free volume $\left(\mathrm{V}_{\mathrm{f}}\right)$ and internal pressure $\left(\pi_{\mathrm{i}}\right)$ at different temperatures are reported in the table 1 .

Table 1. Summary of experimental data: Density $(\rho)$, ultrasonic velocity $(u)$, viscosity $(\eta)$, and the derived acoustical parameters of DMF-EMK mixtures at different temperatures.

\begin{tabular}{|c|c|c|c|c|c|c|c|c|c|c|c|}
\hline $\mathbf{X}_{\text {EMK }}$ & $\underset{\left(\mathrm{ms}^{-1}\right)}{\mathbf{u}}$ & $\begin{array}{c}\rho \\
\left(\mathrm{Kg} \mathrm{m}^{-3}\right)\end{array}$ & $\begin{array}{c}\eta \mathbf{x} 10^{-3} \\
\left(\mathrm{Nm}^{-2} \mathrm{~s}\right)\end{array}$ & $\begin{array}{c}\boldsymbol{\beta x} \mathbf{1 0}-10 \\
\left(\mathrm{Kg}^{-1} \mathrm{~m} \mathrm{~s}^{-1}\right)\end{array}$ & $\begin{array}{c}\mathbf{Z x 1 0} \mathbf{0}^{-6} \\
\left(\mathrm{Kg}^{-1} \mathrm{~m}^{-2} \mathrm{~s}^{-1}\right.\end{array}$ & $\begin{array}{c}\mathbf{L}_{\mathbf{f}} \mathbf{x 1 0} \mathbf{1 0}^{11} \\
(\mathrm{~m})\end{array}$ & $\begin{array}{l}\mathbf{R}_{\mathbf{m}} \mathbf{x} \mathbf{1 0} \mathbf{5}^{\mathbf{5}} \\
\left(\mathrm{m} \mathrm{s}^{-1}\right)^{1 / 3} \\
\left(\mathrm{~m}^{3} \mathrm{~mol}^{-1}\right)\end{array}$ & $\begin{array}{l}\mathbf{W x 1 0} \mathbf{5}^{\mathbf{3}} \\
\left(\mathrm{m}^{3} \mathrm{~mol}\right) \\
\left(\mathrm{Kg}^{-1} \mathrm{~ms}^{2}\right)\end{array}$ & $\begin{array}{c}\tau \times 10^{12} \\
(s)\end{array}$ & $\begin{array}{c}\mathbf{V}_{\mathbf{f}} \mathbf{x} 10^{-8} \\
\left(\mathrm{~m}^{3} \mathrm{~mol}^{-1}\right)\end{array}$ & $\begin{array}{c}\pi \mathbf{i x 1 0}{ }^{9} \\
(\mathrm{~Pa})\end{array}$ \\
\hline \multicolumn{12}{|c|}{ Temperature $298 \mathrm{~K}$} \\
\hline 0.00 & 1456.70 & 944.4 & 0.8025 & 4.99 & 13.76 & 4.59 & 0.8773 & 0.3186 & 5.34 & 5.46 & 1549.77 \\
\hline 0.10 & 1428.00 & 928.5 & 0.7524 & 5.28 & 13.26 & 4.73 & 0.8852 & 0.3210 & 5.28 & 5.82 & 1500.96 \\
\hline 0.20 & 1402.80 & 913.8 & 0.7038 & 5.56 & 12.82 & 4.85 & 0.8929 & 0.3233 & 5.21 & 6.25 & 1451.47 \\
\hline 0.30 & 1376.00 & 899.0 & 0.6629 & 5.87 & 12.37 & 4.98 & 0.9006 & 0.3256 & 5.12 & 6.63 & 1409.17 \\
\hline 0.40 & 1351.10 & 884.8 & 0.6144 & 6.19 & 11.95 & 5.12 & 0.9082 & 0.3279 & 5.01 & 7.22 & 1356.81 \\
\hline 0.50 & 1324.60 & 870.5 & 0.5619 & 6.55 & 11.53 & 5.26 & 0.9159 & 0.3303 & 4.91 & 8.00 & 1298.18 \\
\hline 0.60 & 1300.10 & 856.3 & 0.5210 & 6.91 & 11.13 & 5.40 & 0.9241 & 0.3327 & 4.80 & 8.69 & 1250.01 \\
\hline
\end{tabular}




\begin{tabular}{|c|c|c|c|c|c|c|c|c|c|c|c|}
\hline 0.70 & 1272.60 & 841.7 & 0.4818 & 7.33 & 10.71 & 5.57 & 0.9321 & 0.3351 & 4.71 & 9.44 & 1203.07 \\
\hline 0.80 & 1245.70 & 827.5 & 0.4467 & 7.78 & 10.31 & 5.74 & 0.9402 & 0.3376 & 4.64 & 10.23 & 1159.34 \\
\hline 0.90 & 1218.00 & 813.0 & 0.4138 & 8.29 & 09.90 & 5.92 & 0.9485 & 0.3401 & 4.57 & 11.07 & 1117.02 \\
\hline 1.00 & 1195.60 & 799.9 & 0.3855 & 8.75 & 09.56 & 6.08 & 0.9568 & 0.3425 & 4.50 & 11.94 & 1078.22 \\
\hline \multicolumn{12}{|c|}{ Temperature 308K } \\
\hline 0.00 & 1424.20 & 934.6 & 0.7103 & 5.28 & 13.31 & 4.81 & 0.8792 & 0.3194 & 5.00 & 6.34 & 1513.49 \\
\hline 0.10 & 1395.20 & 918.9 & 0.6565 & 5.59 & 12.82 & 4.95 & 0.8876 & 0.3217 & 4.89 & 6.90 & 1455.90 \\
\hline 0.20 & 1368.40 & 904.1 & 0.6118 & 5.91 & 12.37 & 5.09 & 0.8951 & 0.3240 & 4.82 & 7.43 & 1406.13 \\
\hline 0.30 & 1341.50 & 889.3 & 0.5705 & 6.25 & 11.93 & 5.23 & 0.9027 & 0.3263 & 4.75 & 8.00 & 1358.55 \\
\hline 0.40 & 1316.00 & 874.6 & 0.5295 & 6.60 & 11.51 & 5.38 & 0.9108 & 0.3287 & 4.66 & 8.67 & 1308.94 \\
\hline 0.50 & 1289.80 & 860.2 & 0.4915 & 6.99 & 11.10 & 5.53 & 0.9187 & 0.3311 & 4.58 & 9.39 & 1261.64 \\
\hline 0.60 & 1263.80 & 846.0 & 0.4554 & 7.41 & 10.69 & 5.70 & 0.9265 & 0.3335 & 4.49 & 10.19 & 1216.84 \\
\hline 0.70 & 1235.60 & 831.8 & 0.4225 & 7.87 & 10.28 & 5.88 & 0.9340 & 0.3357 & 4.44 & 11.00 & 1172.43 \\
\hline 0.80 & 1206.40 & 817.5 & 0.3914 & 8.40 & 09.86 & 6.07 & 0.9416 & 0.3380 & 4.39 & 11.88 & 1130.54 \\
\hline 0.90 & 1178.80 & 802.7 & 0.3614 & 8.97 & 09.46 & 6.27 & 0.9503 & 0.3406 & 4.32 & 12.91 & 1087.45 \\
\hline 1.00 & 1153.30 & 788.8 & 0.3378 & 9.53 & 09.10 & 6.46 & 0.9587 & 0.3431 & 4.29 & 13.80 & 1052.29 \\
\hline \multicolumn{12}{|c|}{ Temperature 318K } \\
\hline 0.00 & 1386.70 & 925.8 & 0.6348 & 5.62 & 12.84 & 5.05 & 0.8806 & 0.3196 & 4.75 & 7.21 & 1487.68 \\
\hline 0.10 & 1360.20 & 909.9 & 0.5825 & 5.94 & 12.38 & 5.19 & 0.8888 & 0.3221 & 4.61 & 7.95 & 1424.64 \\
\hline 0.20 & 1334.80 & 894.8 & 0.5408 & 6.27 & 11.94 & 5.34 & 0.8969 & 0.3245 & 4.52 & 8.62 & 1372.52 \\
\hline 0.30 & 1305.10 & 879.9 & 0.5006 & 6.67 & 11.48 & 5.51 & 0.9040 & 0.3267 & 4.45 & 9.34 & 1322.72 \\
\hline 0.40 & 1275.80 & 864.7 & 0.4633 & 7.11 & 11.03 & 5.68 & 0.9117 & 0.3290 & 4.39 & 10.11 & 1274.19 \\
\hline 0.50 & 1249.60 & 849.8 & 0.4269 & 7.54 & 10.62 & 5.85 & 0.9202 & 0.3316 & 4.29 & 11.06 & 1223.40 \\
\hline 0.60 & 1222.50 & 835.3 & 0.3940 & 8.01 & 10.21 & 6.03 & 0.9281 & 0.3340 & 4.21 & 12.05 & 1176.60 \\
\hline 0.70 & 1195.70 & 820.9 & 0.3665 & 8.52 & 09.81 & 6.22 & 0.9361 & 0.3364 & 4.16 & 12.96 & 1136.05 \\
\hline 0.80 & 1165.00 & 806.5 & 0.3388 & 9.14 & 09.40 & 6.44 & 0.9434 & 0.3386 & 4.13 & 14.00 & 1095.18 \\
\hline 0.90 & 1135.9 & 791.8 & 0.3147 & 9.79 & 08.99 & 6.67 & 0.9515 & 0.3410 & 4.11 & 15.03 & 1057.62 \\
\hline 1.00 & 1110.30 & 776.6 & 0.2936 & 10.45 & 08.62 & 6.89 & 0.9615 & 0.3439 & 4.10 & 16.08 & 1021.64 \\
\hline
\end{tabular}

\section{Adiabatic Compressibility}

The plots of the adiabatic compressibility $(\beta)$ against mole fraction of EMK of $\mathrm{EMK}+\mathrm{DMF}$ binary mixture at different temperatures are given in figure 1 . The adiabatic compressibility $(\beta)$ increases with the increase in content of EMK in the mixture at all the temperatures. This trend shows that the molecular attraction are more at lower concentration of EMK and higher concentrations the attractions are less due to steric hindrance and for 
$\mathrm{EMK}+\mathrm{DMF}$ system the dipole- dipole interactions/associations between EMK and DMF molecules are more at higher temperature than at lower temperature. Similar observations were made by Syal et $\mathrm{al}^{15}$ and Kumar et $\mathrm{al}^{16}$. With the increase of temperatures, $\beta$ - values of mixture increase, indicating temperature dependence of $\beta$ and increase of interactions between molecules of solvents mixture.

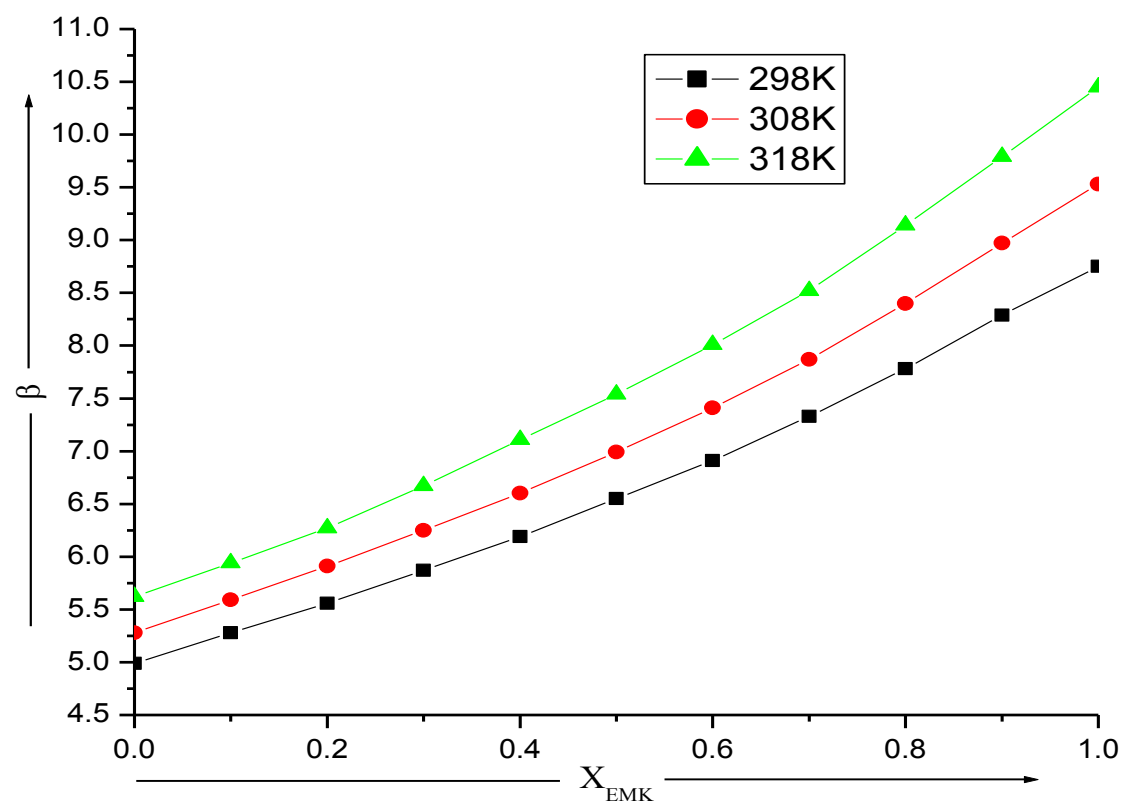

Figure 1: Plots of Adibatic compressibility $(\beta)$ versus Mole Fraction of EMK $\left(\mathrm{X}_{\mathrm{EMK}}\right)$ at different temperatures.

\section{Intermolecular Free Length $\left(\mathbf{L}_{\mathrm{f}}\right)$}

The free length of system is a measure of intermolecular interaction between the components in the binary mixtures. The increase in free length indicates weakening of intermolecular attraction. The velocity of ultrasonic waves should increase if the intermolecular free length decreases as a result of mixing of two components. Erying and Kincaid ${ }^{17}$ have proposed that $\mathrm{L}_{\mathrm{f}}$ is a predominating factor in determining the variation of ultrasonic velocity in solutions. The change in free length also indicates that there is significant interaction between the solute and solvent molecules due which structural arrangement is also affected.

The intermolecular free length $\left(\mathrm{L}_{\mathrm{f}}\right)$ values decreases with increase in concentration of DMF in EMK+DMF binary system at all the temperatures which shows that dipole-dipole interactions are more at higher concentration of DMF in all the systems ${ }^{18}$. With increase in temperature, the magnitude of $\mathrm{L}_{\mathrm{f}}$ increases showing the presence of solute-solvent interactions. Similar observations were made by Syal et $\mathrm{al}^{15}$ and $\mathrm{Ali}^{18}$. Figure- 2 contains plots of intermolecular free length $\left(\mathrm{L}_{\mathrm{f}}\right)$ against mole fraction of EMK for EMK+DMF mixtures at 303,308 and $318 \mathrm{~K}$. 


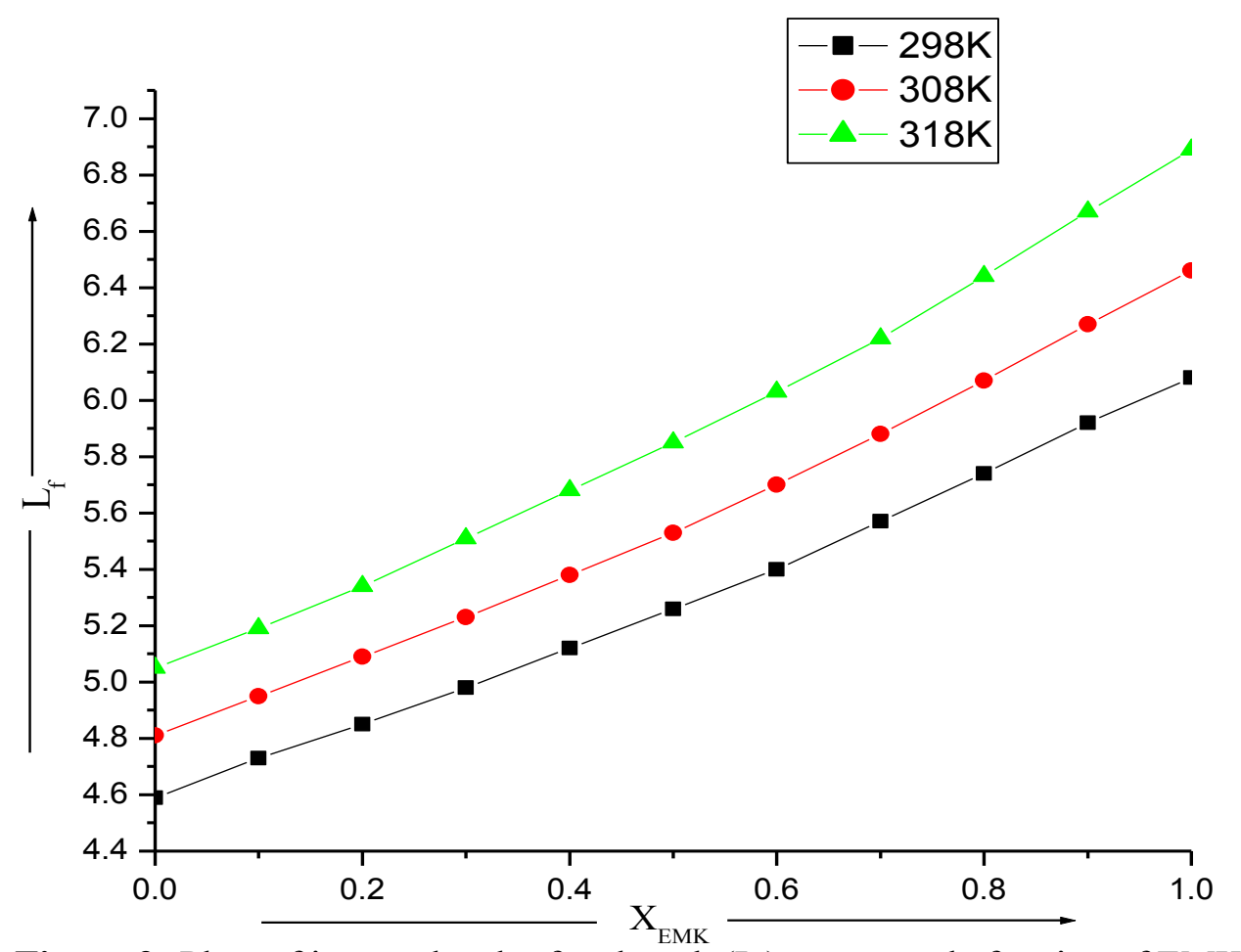

Figure 2: Plots of intermolecular free length $\left(\mathrm{L}_{\mathrm{f}}\right)$ versus mole fraction of EMK $\left(\mathrm{X}_{\mathrm{EMK}}\right)$ at different temperatures.

\section{Acoustic Impedance (Z)}

The acoustic impedance decreases uniformly with the increase in the concentration of EMK in EMK+DMF system at all the temperatures as shown in Figure-3. This is in agreement with the theoretical requirement as both ultrasonic velocity $(u)$ and density $(\rho)$ decrease with increase of the concentration of EMK.

With increase of temperature, $Z$ values decrease for all the studied mixtures, this is in accordance with $u$ and $\rho$, as both $u$ and $\rho$ decrease with increase with temperatures.

$Z$ values decrease with the decrease of EMK content to EMK+DMF mixture. This may be due to change of intermolecular and solute - solvent interaction between EMK and DMF molecules with the addition of EMK to DMF in mixture ${ }^{18}$. 


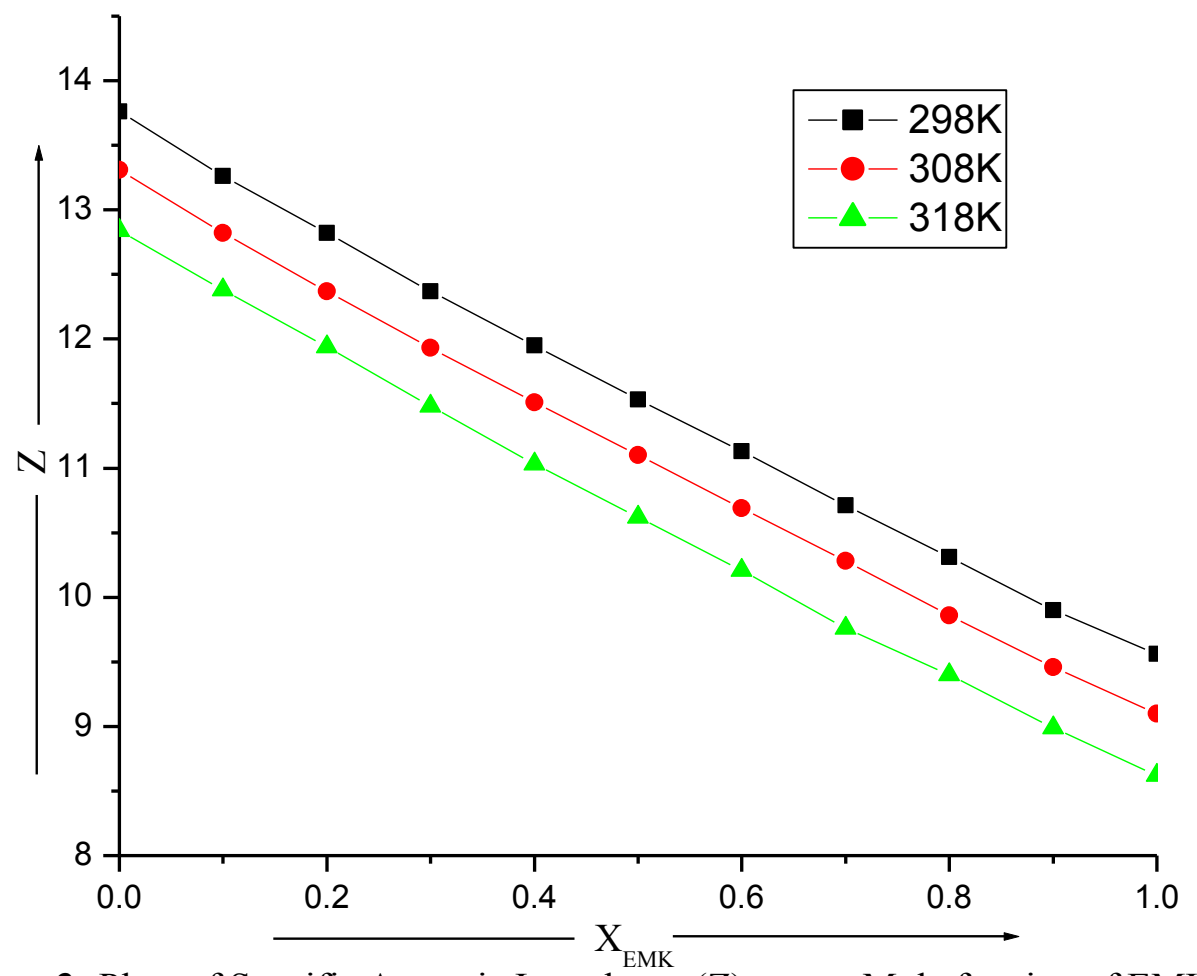

Figure 3: Plots of Specific Acoustic Impedance $(Z)$ versus Mole fraction of EMK $\left(X_{\mathrm{EMK}}\right)$ at different temperatures.

\section{Molar Sound Velocity $\left(R_{m}\right)$ and Wada's constant(W)}

The plots of molar sound velocity (Rao's constant) $\left(\mathrm{R}_{\mathrm{m}}\right)$ and molar adiabatic compressibility (Wada constant) (W) with mole fraction of EMK in the binary mixtures of $\mathrm{EMK}+\mathrm{DMF}$ at different temperatures has been given in figures 4 and 5 respectively. The Rao' constant and wada's constant values are increases with increase in concentration of EMK and increase with increase in temperature and indicate the solute solvent interaction may be occur ${ }^{20}$ in the system. Further, the linear variation indicate the absence of complex formation $^{21,22}$ in the liquid mixture. 


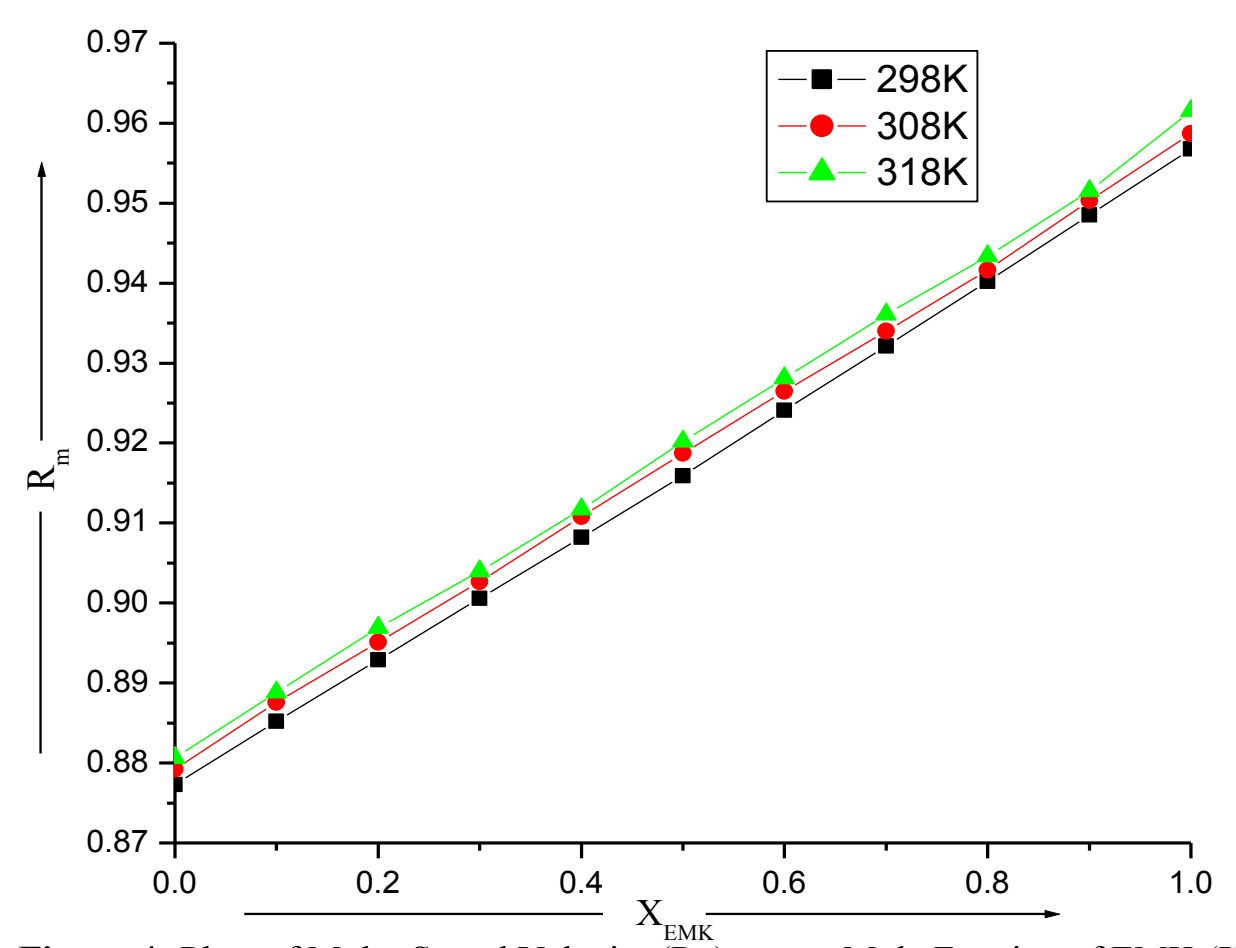

Figure 4: Plots of Molar Sound Velocity $\left(\mathrm{R}_{\mathrm{m}}\right)$ versus Mole Fraction of EMK $\left(\mathrm{X}_{\mathrm{EMK}}\right)$ at different temperatures.

\section{Relaxation Time $(\tau)$}

Further evidence of dipole- dipole type of interactions in EMK+DMF solvent system is reflected in relaxation time $(\tau)$ as shown in figure-6. The relaxation time $(\tau)$ values show a regular decrease with mole fraction of EMK with slight deviation in linearity at 60 mole \% EMK at all the temperatures, the non-linearity, however, becomes more marked at higher temperatures.

This behavior is found to be same as for DMF+DMSO system but is contrary to $\mathrm{DMSO}+\mathrm{MeOH}$ and $\mathrm{DMF}+\mathrm{MeOH}$ solvent system ${ }^{23}$. However, the decrease in $\tau$ values for EMK+DMF system with increase of temperature is found to be consistent with $\mathrm{DMSO}+\mathrm{MeOH}$ and $\mathrm{DMF}+\mathrm{MeOH}$ systems $^{23}$ and also for DMF+DMSO system. 


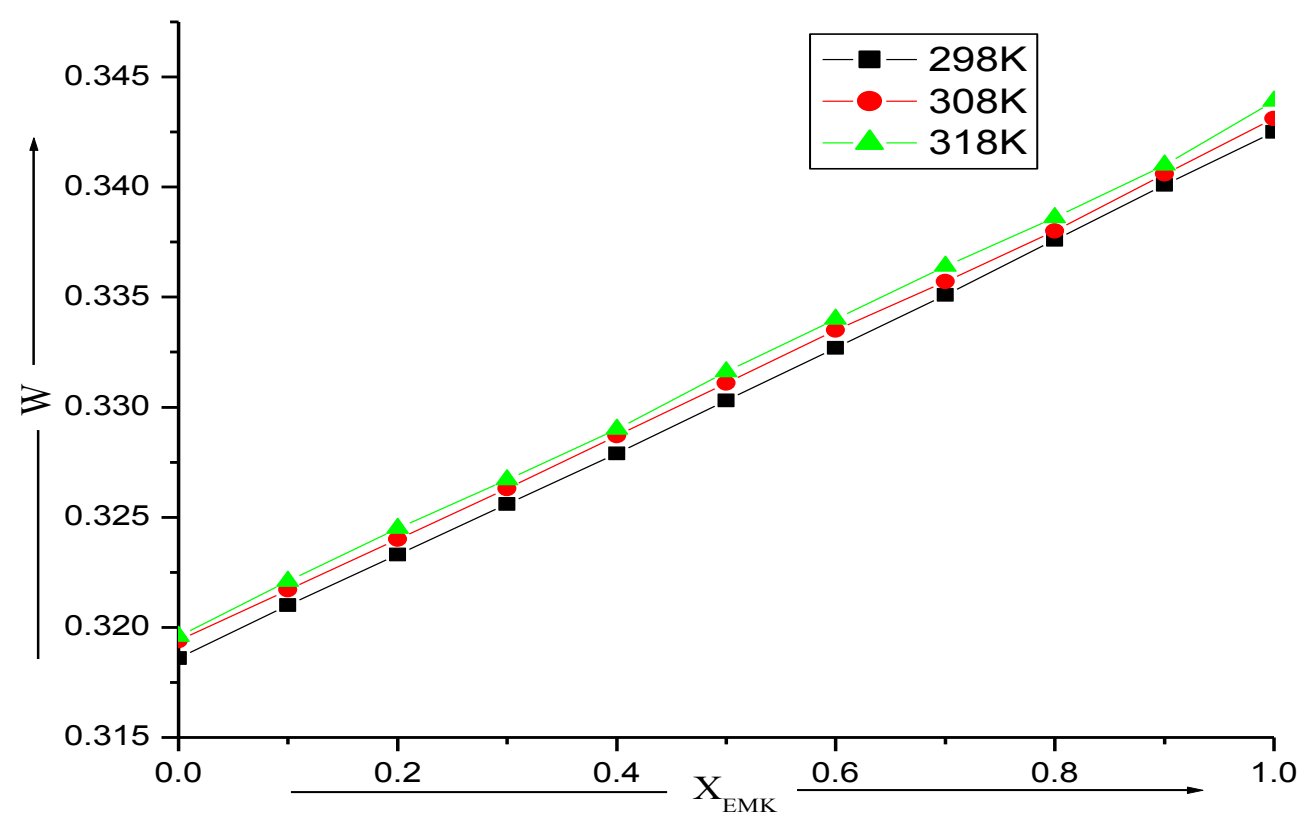

Figure 5: Plots of Wada's Constant $(W)$ versus Mole Fraction of EMK $\left(\mathrm{X}_{\mathrm{EMK}}\right)$ at differents Temperatures.

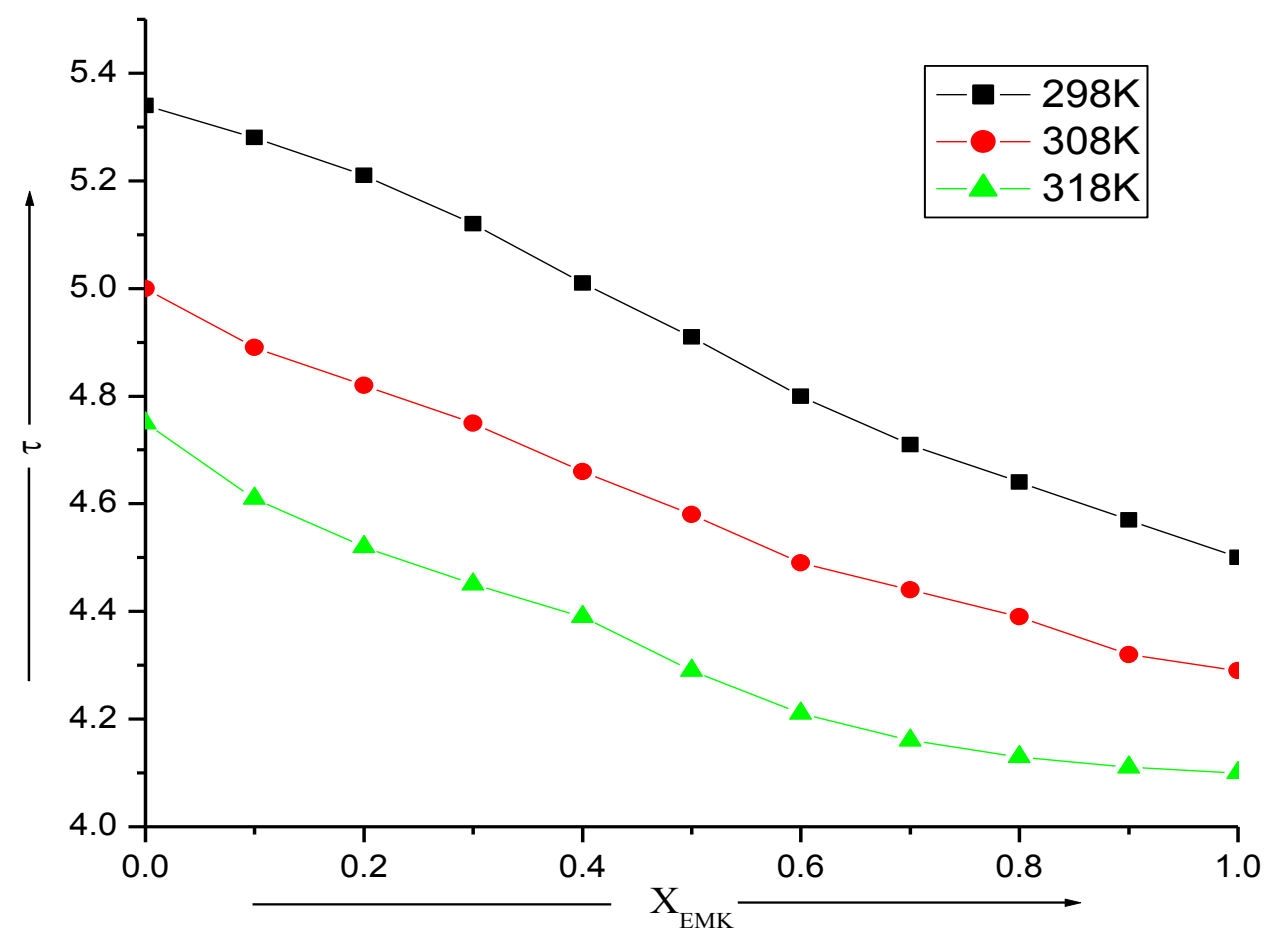

Figure 6: Plots of Relaxation Time ( $\mathrm{t}$ ) versus Mole Fraction of EMK $\left(\mathrm{X}_{\mathrm{EMK}}\right)$ at different temperatures. 


\section{Free Volume $\left(\mathbf{V}_{\mathrm{f}}\right)$}

Figure-7 contains plots of free volume against mole fraction of EMK for EMK+DMF solvent system at different temperatures. $V_{f}$ values increase with the increase of EMK content in $\mathrm{EMK}+\mathrm{DMF}$ mixture. Increase of temperature also increases the magnitudes of $\mathrm{V}_{\mathrm{f}}$.

This behavior of $V_{f}$ is opposite to that observed for internal pressure $\left(\pi_{i}\right)$ with regard to composition of solvent system and increase of temperature. Similar behavior has been reported in DMSO $+\mathrm{H}_{2} \mathrm{O}$ system ${ }^{24}$.

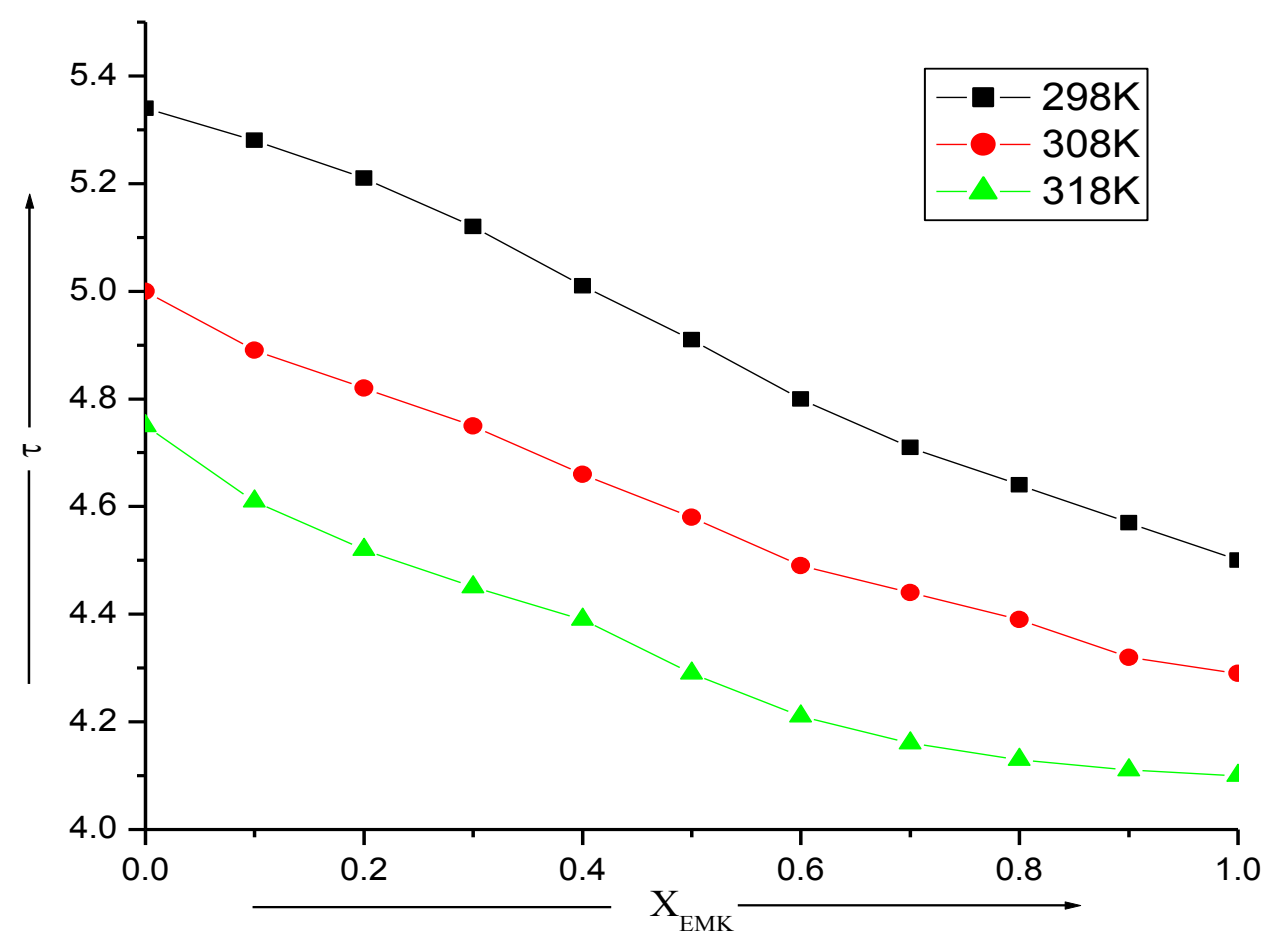

Figure 6: Plots of Relaxation Time $(\mathrm{t})$ versus Mole Fraction of EMK $\left(\mathrm{X}_{\mathrm{EMK}}\right)$ at different temperatures.

\section{Internal Pressure $(\pi \mathrm{i})$}

Internal pressure $(\pi \mathrm{i})$ in a binary liquid mixture is a measure of cohesive forces between the components. Figure- 8 contains the plots of internal pressure against mole fraction of EMK for EMK + DMF system at different temperatures. $\pi \mathrm{i}$ decrease with the increase of content of $\mathrm{EMK}$ in the EMK + DMF system and also decrease with rise in temperature. This predicts the presence of solute- solvent interactions.

Internal pressure $(\pi \mathrm{i})$ decreases with rise in temperature because of thermal agitation of ion from each other due to increasing thermal energy, which reduces the possibility for interactions and reduces the cohesive forces and ultimately leads to a decrease in the internal pressure. Similar observations were made by Chauhan et $\mathrm{al}^{25}$ 


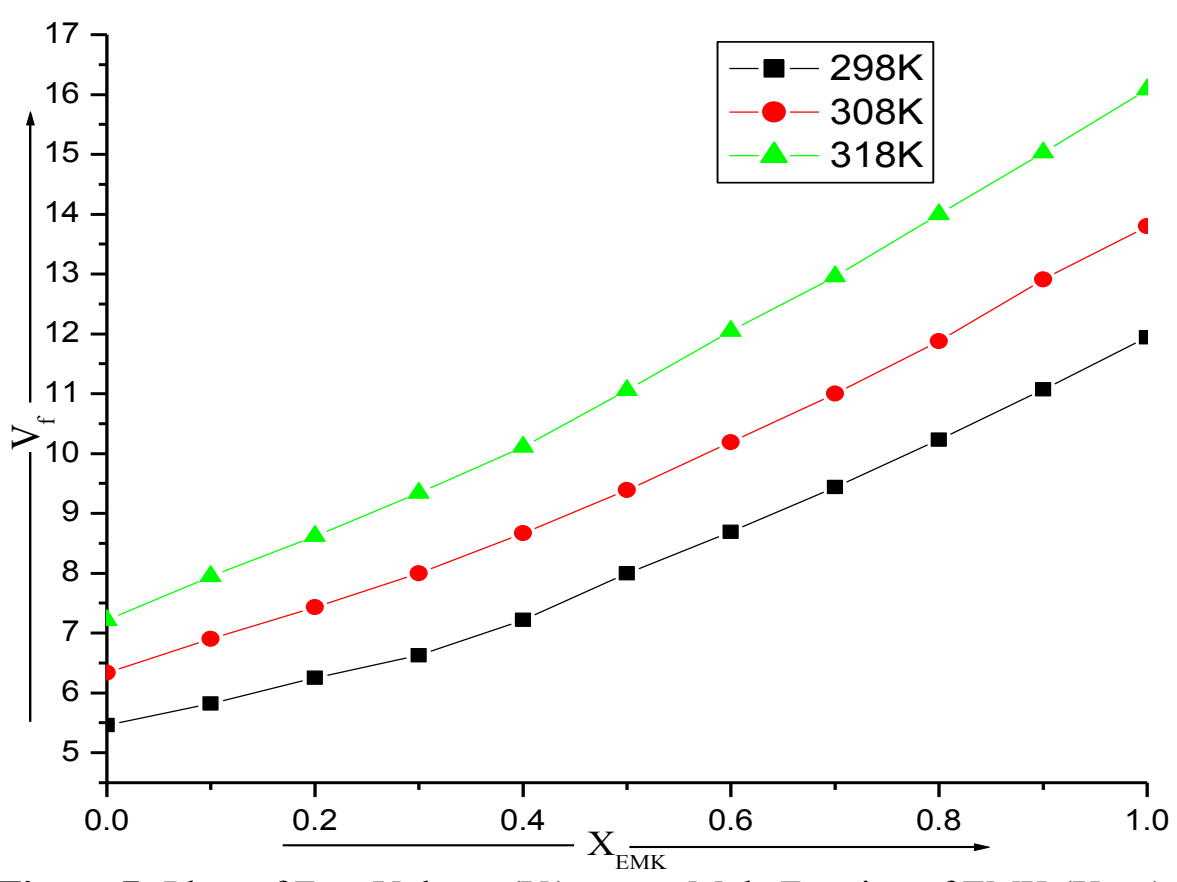

Figure 7: Plots of Free Volume $\left(\mathrm{V}_{\mathrm{f}}\right)$ versus Mole Fraction of EMK $\left(\mathrm{X}_{\mathrm{EMK}}\right)$ at different temperatures.

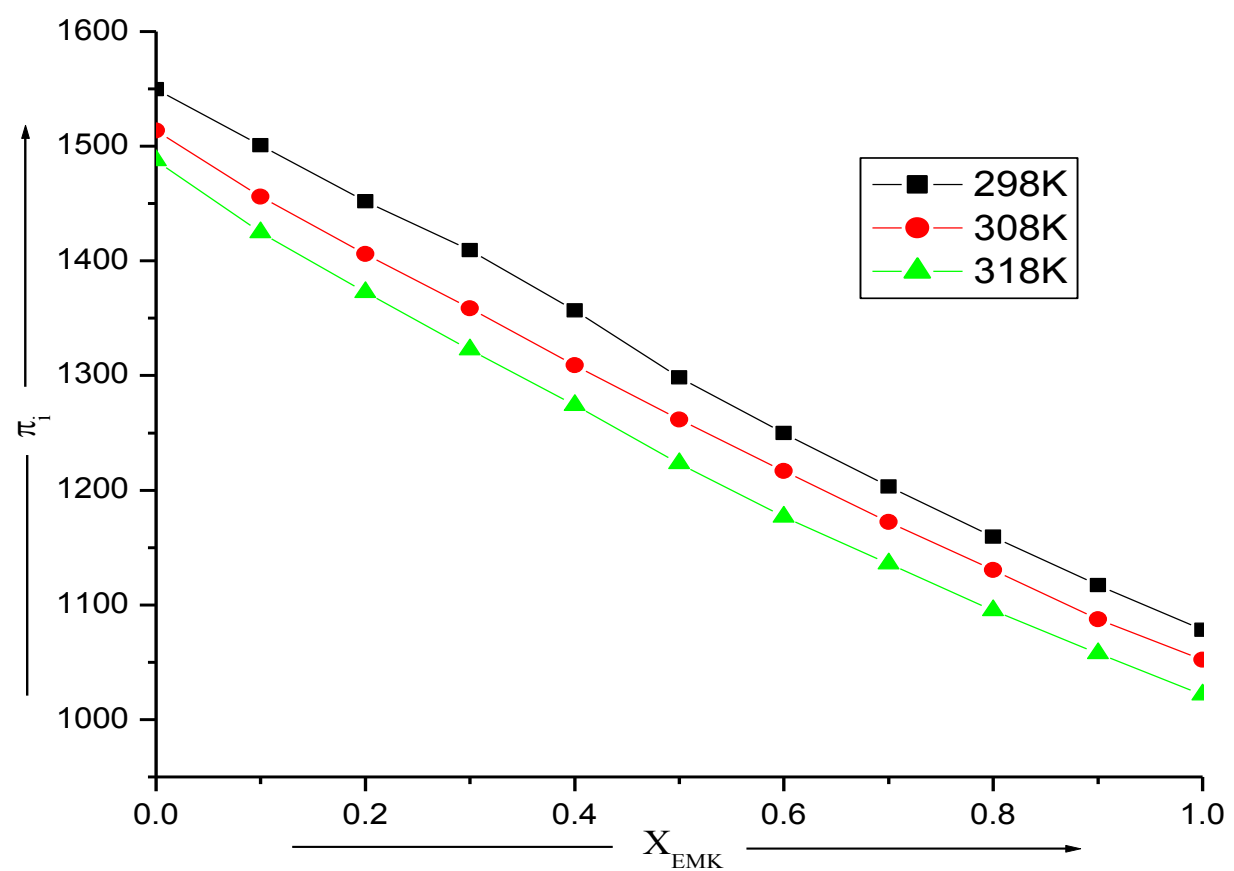

Figure 8: Plots of Internal Pressure $\left(\pi_{i}\right)$ versus Mole Fraction Of EMK $\left(\mathrm{X}_{\mathrm{EMK}}\right)$ at different temperatures. 


\section{References}

[1] Grigorev S.B., Manucharov S.Y. and Masnucharov S.A., Vysokomol Soedin, Ser B, (USSR), 28, (1986)150.

[2] Hautman, P.H., Saeuberlich R. and Schlothauer K., (Germany),25,(1984)985.

[3] Jacobson B., Acta Chem. Scand, 5(1951)1214; 6(1952)1485;J. chem.. Phys. 20(1952)927.

[4] Ali A., Hyder S. and Nain A.K., Acoustic let. 21(1998)21;J. Mol. Liq.79(1991)89; Indian J. Phys. B74(2000)63.

[5] Kannappan V. and Jaya Santhi R, Indian J. Pure Appl. Phys.,43(2005)750.

[6] Ali A., Nain A.K. and Kamil M, Thermochim Acta, 274(1986)209.

[7] Kinginger J.B., Tannahill M.M., Greenberg M.S. and Popov A.I., J. Phys. Chem., 77(1973)2444.

[8] Hill N.E. \& Vanghan W.E., Dielectric properties and Molecular Behaviour. (Van Nostrand. New York),(1969)31.

[9] Syal V.K., Lal G., Bist P. \& Chauhan S., J. Mol. Liq., 63(1995)317.

[10] Syal V.K., Bajaj J.M., Chauhan S. \& Chauhan M. S., J. Indian Chem. Soc.,69(1992)807.

[11] Syal V.K., Patial B. S. \& Chauhan S., Acoustics Letters,23(7)(2000)137.

[12] Syal V.K., Chauhan Anita \& chauhan Suvarcha, J. Pure Appl. Ultrason.27(2005)61-69.

[13] Kumar G. Pavan, Babu Ch. Praveen, Samatha K., Jyosthna N., Showrilu K., International Letters of Chemistry, Physics and Astronomy 10(2014)25-37.

[14] Eyring H. and Kincaid J.F.,J.Chem.,6(1928)620.

[15] Syal V K, Chauhan S \& Uma Kumari, Indian J. pure Appl. Phys., $43(2005) 844$.

[16] Kumar R, S. Jayakumar \& Kannappan, Indian J. pure Appl. Phys., 46(2008)169-175.

[17] Erying H and Kincaid J.F.; J. Pure \& Appl. Ultrason., 6(1938)620.

[18] Ali Askar S.J.; Journal of Chemical and Pharmaceutical Research,4(1)(2012)617-632.

[19] Chauhan M.S., Sharma M, Gupta S., Kumar A. and Chauhan S.; Czech. Chem. Commun.,60(1995)43.

[20] Peter Hauptmann, Ralph Sauberlich and Klaus Schlothauer Polymer, vol 25 (1984) 985.

[21] Chauhan S., Syal V.K. and Chauhan M S, Indian J. Pure Appl. Phys. 33(1995) 92.

[22] Tong Jie and Dong Yan-wu and Dong Tian-Kui, Chinese Science Bulletin. 34 (1989) 1262.

[23] Chauhan M. S., Sharma K. C., Gupta S., Sharma M., and Chauhan S.; Acoustic Letters, 18(1995)233.

[24] Syal V.K., Chauhan A.\& Chauahn S.; J Pure And Appl Ultrason,27(2005)192.

[25] Chauhan S. Kuldeep K., Patial B.S.; Indian J Pure \& App. Phys.,51(2013)531-541. 